\title{
One Hundred Years of Arctic Ice Cover Variations as Simulated by a One-Dimensional, Ice-Ocean Model
}

\author{
S. HäKKINEN AND G. L. MelloR
}

Princeton University, Princeton, New Jersey

\begin{abstract}
A one-dimensional ice-ocean model consisting of a second moment, turbulent closure, mixed layer model and a three-layer snow-ice model has been applied to the simulation of Arctic ice mass and mixed layer properties. The results for the climatological seasonal cycle are discussed first and include the salt and heat balance in the upper ocean. The coupled model is then applied to the period 1880-1985, using the surface air temperature fluctuations from Hansen et al. (1983) and from Wigley et al. (1981). The analysis of the simulated large variations of the Arctic ice mass during this period (with similar changes in the mixed layer salinity) shows that the variability in the summer melt determines to a high degree the variability in the average ice thickness. The annual oceanic heat flux from the deep ocean and the maximum freezing rate and associated nearly constant minimum surface salinity flux did not vary significantly interannually. This also implies that the oceanic influence on the Arctic ice mass is minimal for the range of atmospheric variability tested.
\end{abstract}

\section{INTRODUCTION}

The main goal of this paper is to explore the behavior of the ice-upper ocean system on climatic time scales and especially the asymmetry of the freezing and melting seasons. We study here only the Arctic ice cover, which is a prominent climate indicator since it contains a large multiyear ice component. Also, a goal is to further test the one-dimensional ice-ocean model of Mellor and Kantha [1989] (hereinafter referred to as MK), in which a change in a boundary condition at the ice-ocean interface has been implemented.

The influence of the polar ice cover on climate derives mainly from the fact that the ice cover can insulate the ocean and thereby modify the surface heat flux by an order of magnitude. The insulating effect depends on the reflective properties of the ice surface, the ice concentration, and the ice thickness [Maykut, 1978, 1982; Maykut and Untersteiner, 1971]. Climate models are shown to have a strong sensitivity to snow and ice cover albedo in Polar regions [Manabe and Stouffer, 1980].

Leads are very important to climate response, since they release heat to the atmosphere in the wintertime and, as a secondary effect, lower the surface albedo. Heat loss through a $1 \%$ lead area can be as large as the conductive loss through the remaining $99 \%$ of the area covered by thick ice. The estimates for lead area range from 1 to $5 \%$ for winter months. Variability in the lead area has been shown to affect considerably the surface air temperatures in climate models [Ledley, 1988a, b].

Monitoring the changes in ice cover have been limited to records of ice extent and concentration in the marginal ice zones before the advent of satellites in the 1970s [Walsh and Johnson, 1979] or to a local ice index such as compiled for the Icelandic coastal waters [Sigtryggson, 1972]. The latter record beginning in 1900 shows that there are periods with extremely heavy ice around 1910 and in the end of the 1960s. Remote sensing techniques have now made it possible to monitor the ice concentration changes from space (e.g., the

Copyright 1990 by the American Geophysical Union.

Paper number $90 \mathrm{JC} 00754$.

0148-0227/90/90JC-00754\$05.00 passive microwave sensors such as electrically scanning microwave radiometer (ESMR), [Parkinson et al., 1987], scanning multichannel microwave radiometer (SMMR), or special sensor microwave/imager (SSM/I)). The ice thickness variations pose a much more difficult monitoring task. Even though SMMR and SSM/I can resolve thin ice and multiyear ice components of the ice concentration, they cannot measure actual thickness of the sea ice. Upward looking sonar along submarine tracks has been the only measurement able to give a large-scale survey of the ice thickness variability in the Arctic [Bourke and Garrett, 1987; Wadhams, 1988].

On climatic time scales the ice thickness is an important factor in controlling the conductive heat flux through ice and thus the salinity flux to the ocean arising from bottom ice accretion. Because ice stores and releases fresh water, the ice thickness and concentration variations, which determine the ice mass, are important quantities in the hydrological cycle. (Note, however that the freshwater reservoir of Arctic ice is a thousand times smaller than that of the Greenland ice sheet [Goody, 1980]. This sea ice-fresh water source can affect the subpolar gyre, mainly through the ice exported from the Arctic to the Greenland Sea, and can significantly modify the oceanic surface layers in the areas conducive to water mass modification such as in the Greenland, Iceland, and Labrador seas [Swift and Aagaard, 1981].

The ice export from the Arctic through the Fram Strait depends also on the winds and ocean currents in the outflow region. Estimates of yearly averaged areal outflows are $0.9 \times$ $10^{6} \mathrm{~km}^{2}$ [Vowinckel, 1964], $0.84 \times 10^{6} \mathrm{~km}^{2}$ [Moritz, 1988], and $1.55 \times 10^{6} \mathrm{~km}^{2}$ [Vinje and Finnekåsa, 1986]. Largescale ice-ocean models have predicted the ice export to vary up to a factor of 3 interannually, with a mean of $1400 \mathrm{~km}^{3}$ for volumetric and a mean of $0.63 \times 10^{6} \mathrm{~km}^{2}$ for the areal export [Walsh et al., 1985]. The ice export variability in the model of Walsh et al. is very sensitive to the wind forcing, which contributes $75 \%$ to the ice drift. This is in contrast to estimates where wind and current drift portions are $30 \%$ and $70 \%$, respectively, as derived from observed buoy drifts and geostrophic winds [Moritz, 1988]. Empirical models for the ice outflow based on the air pressure difference across the Fram Strait suggest that the wind-driven flow may have 
varied by a factor of 2 during the period 1950-1983 [Englebretson and Walsh, 1989]. The lack of knowledge on the current variability obviates more precise conclusions on the total ice export variability during that period.

The ice export through the Fram Strait makes the Arctic a net ice source accompanied by a net brine rejection to the mixed layer in the Arctic basin. There are several sources which compensate this salinity increase and produce a stable stratification. The largest inflow source to the upper layer is the Pacific waters through the Bering Strait, 1.5 Sv according to Aagaard and Greisman [1975]; the salinity of this water is 32.4 ppt. Of more importance to the salinity budget is the 0.1 $\mathrm{Sv}$ of river runoff [Aagaard and Greisman, 1975]. The snowfall rate over the Polar sea ice is a poorly known quantity, both spatially and temporally. Maykut and Untersteiner [1971] estimate about $40 \mathrm{~cm}$ yearly snow accumulation, the equivalent of $0.05 \mathrm{~Sv}$ of fresh water. Therefore in terms of salt fluxes, combined river runoff and precipitation is the largest component in the salt balance to compensate the net brine rejection.

Earlier modeling experiments show that large variations in the fresh water sources, such as the planned Soviet river diversions, can modify the Arctic ice cover [Semtner, 1987]. A study by Stigebrandt [1981] suggests that a removal of the Bering Sea inflow may even be catastrophic for the stable stratification on which the existence of the year-round sea ice cover is dependent. The one and one-half layer model of Killworth and Smith [1984] shows how various inflows affect the stable stratification.

The one-dimensional ice-ocean model used in this study was developed by Mellor and Kantha [1989]. The snow-ice model is an extension of the Maykut and Untersteiner [1971] and Semtner [1976] thermodynamic models, which are forced by winds and monthly air temperatures and monthly climatological humidities and snowfall rates. Here, however, ice concentration is included as a prognostic variable. The ocean model contains only the upper water column of $80 \mathrm{~m}$, at the bottom of which the temperature and salinity are fixed at values $-1.54^{\circ} \mathrm{C}$ and $32.65 \mathrm{ppt}$ from the region north of $83^{\circ} \mathrm{N}$. The one-dimensional model represents the areaaveraged Arctic basin and is driven by area-averaged surface forcing. The turbulent mixing coefficients are determined by the Mellor-Yamada, level $2 \frac{1}{2}$, turbulence closure scheme. As was discussed above, the ice export through the Fram Strait is important to the mass balance. In the model, the areal ice export is a constant and appears as a sink term in the ice concentration and total mass equations. This sink term requires the Arctic to be a net ice production area, which also means that there must be a net salinity input to the mixed layer.

In section 2 we first discuss the one-dimensional model, while referring to MK for many details. In section 3, the surface forcing is described for both a seasonal climatology and the subsequent, 100-year calculation. Results of two calculations based on these surface forcings are described in section 4 .

\section{THE ICE-OCEAN MODEL}

\section{Ice Model}

The one-dimensional model used in this study is described in detail by MK. The prognostic properties of the ice model
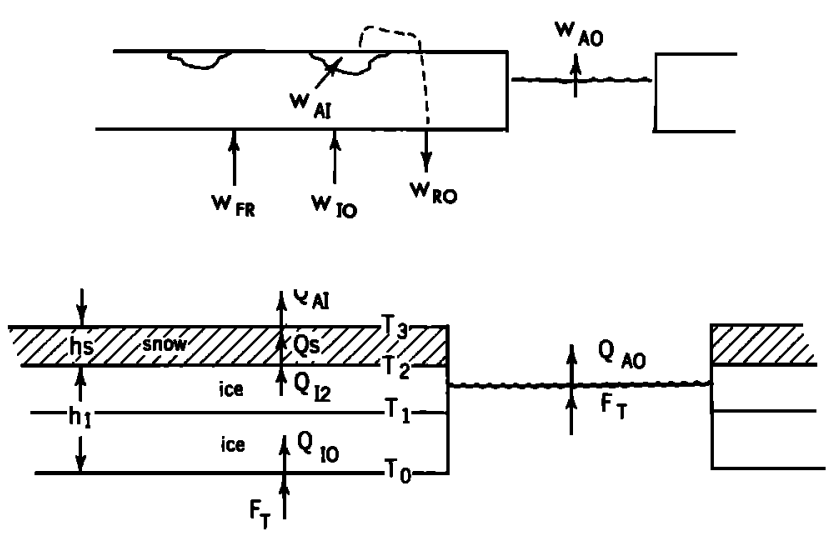

Fig. 1. Schematic view of the thermodynamics in the snow-iceocean system: (top) volume fluxes and (bottom) heat fluxes. $F_{T}$ is the heat exchanged across the surface (the left-hand side of (9)).

are ice thickness, concentration, velocity, and internal energy. The ice thermodynamics is a three-layer representation where, as is shown in Figure 1, temperatures at the surface (snow or ice), in the ice interior, and at the bottom are calculated. A short overview of the model is given below, including some modifications which are introduced in this paper.

The ice model part is composed of the momentum equations for the ice velocity vector $U_{I i}$,

$$
\begin{aligned}
& \frac{\partial\left(A h_{I} U_{I i}\right)}{\partial t}=A h_{I} \varepsilon_{i j k} f_{j} U_{I k}+A \frac{\left(\tau_{A I i}-\tau_{I O i}\right)}{\rho_{I}} \text { (1) } \\
& i=1,2
\end{aligned}
$$

In the present application the only role of ice velocity is to produce mixed layer stress and turbulence. The equations for mass $A h_{I}$ and concentration $A$ are

$$
\begin{aligned}
& \frac{\partial\left(A h_{I}\right)}{\partial t}+A h_{I} \operatorname{div} U_{I}=\frac{\rho_{0}}{\rho_{I}} \\
& \cdot\left[A\left(W_{I O}-W_{A I}\right)+(1-A) W_{A O}+W_{F R}\right]
\end{aligned}
$$

$$
\begin{aligned}
& h_{I} \frac{\partial A}{\partial t}+A \operatorname{div} U_{I}=\frac{\rho_{0}}{\rho_{I}} \\
& \cdot\left[\Phi(1-A) W_{A O}+\Psi A W_{I O} H\left(-W_{I O}\right)+(1-A) W_{F R}\right]
\end{aligned}
$$

In these equations $f_{j}=(0,0, f)$ is the Coriolis parameter; $\rho_{I}$ and $\rho_{0}$ are the ice and water density, respectively. $\tau_{A I}$ and $\tau_{I O}$ are the atmospheric air-ice and interfacial ice-water stresses; and $h_{I}$ is the average ice thickness. In equations (2) and (3), the volumetric flux $W_{A O}$ at the air-water interface can only be positive, as is discussed below, and accounts for freezing of open water; $W_{A I}$ is the flux at the air-ice interface wherein surface ice melts (positive value) or surface trapped water freezes (negative value) in the fall; $W_{I O}$ is the freeze or melt rate (positive or negative value) of ice at the ice-water interface; and $W_{F R}$ is the frazil ice production in the water column. $H\left(-W_{I O}\right)$ is the Heaviside function, which is zero when $W_{I O}$ is positive (freezing condition) and unity otherwise. The two parameters $\Phi$ and $\Psi$ are empirically chosen to model the effects of melting and freezing in the ice concentration equation. 
A modification of MK's surface boundary condition for the ocean (as discussed later on) requires that $W_{A O}$ be always greater than or equal to zero. The choices for the freezing parameter $\Phi$ in equation (3) are discussed by MK; and Kantha; $\Phi=1$ allows only ice buildup at the edges of the ice cover and preserves the ice thickness when $A<1$; larger values of $\Phi$ allow for thickness changes. The previous modeling experiments suggest that results are insensitive to $\Phi$ so long as $\Phi \geq 2$; we set $\Phi=4$ here. A corresponding coefficient by Hibler's [1979] model depends also on ice thickness.

The second term on the right-hand side of (3) is active only when ice is melting, i.e., the term is negative or null as determined by the Heaviside function. It represents the reduction in ice concentration due to the fact that the thinner ice near the ice edge will be removed first. To determine $\Psi$, we first need to be careful with definitions. First let $g(h)$ be the ice thickness density function such that $g(h) \Delta h$ is the fraction of total ocean area whose thickness is between $h$ and $h+\Delta h ; g(h)$ does not include the open water singularity at $h=0$. Then, we define $\tilde{g}(h)=(1-A) \delta(h)+\int_{0}^{\infty} g(h) d h$ where $\delta(h)$ is the Dirac delta function. The integral $\int_{0}^{\infty} \tilde{g}(h) d h=1$ $=(1-A)+\int_{0}^{\infty} g(h) d h$ and, of course, $\int_{0}^{\infty} g(h)$ $d h=A$. Now, consider a melt rate which is independent of $h$. Therefore in a time interval $\Delta t, g(h, t+\Delta t)=g(h+\Delta h$, t) so that

$\Delta A=\Delta \int_{0}^{\infty} g(h) d h=\int_{0}^{\infty}[g(h+\Delta h, t)-g(h, t)] d h$ $=g(0) \Delta h$

In the limit $\Delta t \rightarrow 0$,

$$
h_{I} \frac{\partial A}{\partial t}=g_{I}(0) h_{I} W_{I o}
$$

where $W_{I O}=\Delta h / \Delta t$ as $\Delta t \rightarrow 0$. Thus $\Psi=g(0) h_{I}$, and we append the Heaviside function in (3), since this process prevails only in the melting case. Observational ice thickness distributions obtained by Bourke and Garrett [1987] gives a value 0.7 for $\Psi$, which we adopt here. Recall that this factor depends on the assumption of a homogeneous melt rate; however, there can exist additional lateral melt where warmer open lead temperatures preferentially melt the sides of the ice floes, an effect more pronounced for smaller floes whose bottom areas are comparable to their sidewall areas. This lateral melt component is not included in the present model.

The thermodynamical part of the ice model is similar to Semtner's [1976] three-layer system, in the sense that snow surface, snow-ice interface, internal ice temperature, and the interfacial ice-ocean temperature are prognostic variables. However, ice concentration is included as a variable, and the thermodynamic model includes provision for matching the ice with an active mixed layer.

In an ensemble of ice thicknesses, here recognized by a single average value $h_{I}$, thin ice gives a disproportionately large contribution to heat conduction. To account for this effect, we multiply the ice conductivity by a factor $G$, which as derived by MK is

$$
G=h_{I} \int_{\varepsilon}^{\infty} g\left(h^{\prime}\right) / h^{\prime} d h^{\prime} \quad \varepsilon=0.1 \mathrm{~m}
$$

The results of Maykut [1982] suggests a value of $G$ around 1.5 , and this value is used in our calculation. However, observed distributions by Bourke and Garrett [1987] yield a value of 2.1 and might persuade us to increase this value (and the concomitant ice thickness) in the future.

The albedos chosen in the model are 0.82 for snowcovered ice without melting, 0.73 for melting snow, and 0.64 for bare ice. For a more detailed description of the ice model, the reader is referred to MK.

\section{Ocean Model and Surface Boundary Conditions}

The full three-dimensional equations for the ocean model are found elsewhere [Mellor and Kantha, 1989; Blumberg and Mellor, 1983, 1987; Oey et al., 1985]; for brevity only one-dimensional equations are cited below. The governing equations for the horizontal velocity components $(U, V)$ and temperature and salinity are

$$
\begin{gathered}
\frac{\partial(U, V)}{\partial t}=f(V,-U)+\frac{\partial}{\partial z}\left[\left(K_{M}+\alpha_{b}\right) \frac{\partial(U, V)}{\partial z}\right] \\
\frac{\partial T}{\partial t}=\frac{\partial}{\partial z}\left[\left(K_{H}+\alpha_{b}\right) \frac{\partial T}{\partial z}\right]+\sigma \frac{L}{C_{p}} \\
\frac{\partial S}{\partial t}=\frac{\partial}{\partial z}\left[\left(K_{H}+\alpha_{b}\right) \frac{\partial S}{\partial z}\right]+\sigma\left(S-S_{I}\right)
\end{gathered}
$$

where $K_{M}$ and $K_{H}$ are the turbulent mixing coefficients for momentum and for heat and salt, and $\alpha_{b}=1.0 \times 10^{-5} \mathrm{~m}^{2}$ $\mathrm{s}^{-1}$ is a small background diffusivity. Using the level $2 \frac{1}{2}$ turbulence closure model of Mellor and Yamada [1974, 1982], $\left(K_{M}, K_{H}\right)=q l\left(S_{M}, S_{H}\right)$ where $\left(S_{M}, S_{H}\right)$ are derived stability factors which are functions of $l^{2} g(\partial \rho / \partial z) /\left(\rho_{0} q^{2}\right)$. In this scheme, twice the kinetic energy, $q^{2}$, and $q^{2} l$ are prognostic variables, where $l$ is the turbulence macroscale. The equations for $q^{2}$ and $q^{2} l$ determine $l$ so that it is asymptotically equal to Prandtl's mixing length near surfaces.

The last term of the right-hand-side of $(5 b)$ accounts for the conversion of sea water into frazil ice whose salinity is $S_{I}$ (for simplicity, $S_{I}$ is taken as the same low value of $4 \mathrm{ppt}$ as congelate ice) and ( $5 a$ ) accounts for the comcomittant energy exchange. The rate of conversion is

$$
\begin{array}{rr}
\sigma=\left[C_{p 0}(m S+n z-T)\right] /\left[L-C_{p 0} m\left(S-S_{I}\right)\right](1 / \tau) \\
m S+n z-T>0 \\
\sigma=0 & m S+n z-T<0
\end{array}
$$

(the right-hand-side of $(5 a, b)$ was, but should not have been, excluded from equations (28) and (29) of MK it was, however, correctly included in the calculations. The derivation of the right-hand-sides of (5) and (6) follows from the development of (33), (34), and (35) of MK (wherein, preceding these equations, $L_{O}$ should be changed to $L_{F}$ ).) The time factor $\tau$ controls the allowable supercooling. If $\tau$ equals the numerical time step, enough frazil ice is created that supercooled water is returned back to the freezing line at every time step, and this has been the practice in this paper and in that of MK. Future wisdom may dictate larger values of $\tau$. We do not maintain frazil ice in the water column but immediately collect it on the surface so that 


$$
W_{F R}=\int \sigma d z
$$

The surface boundary conditions for the ocean model are a combination of fluxes acting on the fractional open water and ice-covered area. For the momentum equations the conditions are

$$
\begin{aligned}
K_{M} \partial(U, V) / \partial z= & A \rho_{0}^{-1}\left(\tau_{I O x}, \tau_{I O y}\right) \\
& +(1-A) \rho_{0}{ }^{-1}\left(\tau_{A O x}, \tau_{A O_{y}}\right) \quad z \rightarrow 0
\end{aligned}
$$

where the interfacial stress $\tau_{I O}$ is computed from

$$
\rho_{0}^{-1}\left(\tau_{I O x}, \tau_{I O y}\right)=\left(U_{I}-U, V_{I}-V\right) \frac{k u_{\tau}}{\ln \left(z / z_{0}\right)}
$$

$$
z \rightarrow 0
$$

The friction velocity $u_{\tau}$ is defined as $\left|\tau_{I O} / \rho_{0}\right|^{1 / 2} ; k$ and $z_{0}$ are von Karman's constant $(=0.4)$ and the roughness parameter, respectively. The roughness parameter $z_{0}$ is chosen to vary linearly with ice thickness; for $3-\mathrm{m}$-thick ice, $z_{0}$ is $2 \mathrm{~cm}$.

The surface heat and salinity flux formulations have been modified relative to the model of MK, and now the new boundary conditions are consistent with the surface momentum flux, where surface flux is an areally weighted combination of the fluxes at the atmosphere-ocean and ice-ocean interfaces. Thus the surface heat flux is

$$
\begin{aligned}
-K_{H} \frac{\partial T}{\partial z}=-A C_{T Z}\left(T_{0}-T\right)+ & (1-A)\left(Q_{A O}\right. \\
& \left.-W_{A O} L_{0} / C_{p 0}\right) \quad z \rightarrow 0
\end{aligned}
$$

where $C_{T 2}$ is the heat exchange coefficient. $T_{0}$ is the skin temperature underneath the ice and equals the freezing point, $Q_{A O}$ is the net surface heat flux (positive upwards), $C_{p 0}$ is the specific heat of seawater, and $L_{0}$ is the latent heat of fusion, which has some dependence on the ice bottom and internal temperature and on the brine fraction. The freezing rate in open water, $W_{A O}$, is specified as

$$
\begin{array}{ll}
W_{A O}=\left(Q_{A O}+\left(K_{H} \frac{\partial T}{\partial z}\right)_{z \rightarrow 0} l \rho_{0} L_{0}\right. & W_{A O}>0 \\
W_{A O}=0 & \text { otherwise }
\end{array}
$$

In the MK version, negative values of $W_{A O}$ were allowed and used to directly melt ice. Now, heat input into leads is absorbed by the mixed layer which, of course, can indirectly contribute to ice melting.

The freezing or melt rate (positive or negative) under the ice is expressed as

$$
W_{1 O}=\left(Q_{1 O}+C_{T z}\left(T_{0}-T\right)\right) / \rho_{0} L_{0}
$$

where $Q_{1 o}$ is the heat flux at the ice-ocean interface. A detailed discussion of the heat and salt exchange coefficients, $C_{T}$ and $C_{S}$, and their dependence on molecular diffusivities, is given by MK and Steele et al. [1989]. As a consequence of this diffusivity dependence, $C_{T z}$ is larger than $C_{S z}$, resulting in supercooling in the water column.

In a similar fashion, the salinity flux at the surface is
TABLE 1. Areally and Monthly Averaged Air Temperature From Crutcher and Meserve [1970] for the Arctic for the Period 1931-1960

\begin{tabular}{cc}
\hline Month & Air Temperature \\
\hline 1 & -29.4 \\
2 & -28.7 \\
3 & -27.6 \\
4 & -21.3 \\
5 & -9.6 \\
6 & -0.5 \\
7 & +2.5 \\
8 & +1.4 \\
9 & -4.6 \\
10 & -13.5 \\
11 & -22.7 \\
12 & -26.9 \\
\hline
\end{tabular}

$$
\begin{aligned}
-K_{H} \frac{\partial S}{\partial z}=-C_{S Z} A\left(S_{0}-S\right) & +(1-A)\left[S_{0}(P-E)\right. \\
+ & \left.W_{A O}\left(S_{I}-S_{0}\right)\right] \quad z \rightarrow 0
\end{aligned}
$$

where $P-E$ is the net precipitation, $S_{I}$ is the ice salinity, and $S_{0}$ is the salinity at the surface. $S_{0}$ is equal to $S$ (the first grid point value below surface) if the grid point is totally free of ice. The sign convention is such that positive flux is upward and acts to freshen the mixed layer.

For the ice-covered region, $S_{0}$ can be solved from the relation whereby the turbulence salinity flux equals the net volumetric salinity flux at the surface. Thus

$$
-C_{S z}\left(S_{0}-S\right)=\left(W_{I O}-W_{R o}\right)\left(S_{I}-S_{0}\right)
$$

$W_{R O}$ is the meltwater drainage in excess of a given level of trapped surface water $(=10 \mathrm{~cm})$. After $S_{0}$ is solved from this relation, $T_{0}$ can be computed at the freezing line, $T_{0}=m S_{0}$, where $m=-0.0543^{\circ} \mathrm{C} / \mathrm{ppt}$. The value $S_{I}=4 \mathrm{ppt}$ is taken as the constant salinity of the ice.

\section{FORCING}

The coupled ice-ocean model is run with a 1.5-hour time step using wind forcing which varies cyclically with a 4-day period so as to simulate passages of low pressure systems. The magnitude of the mean wind is $6 \mathrm{~m} / \mathrm{s}$, which corresponds to the average wind speed given by the monthly climatology by Gorshkov [1983]. The sensible and latent heat flux are computed using bulk formulas, with exchange coefficient of $1.5 \times 0^{-4}$ for open water and $3.0 \times 10^{-4}$ for ice cover. The same values are used for the momentum exchange coefficients. A climatological seasonal, ice, and ocean equilibrium is first established using the forcing described in the following: Cloudiness is chosen to be the monthly climatology as derived by Parkinson and Washington [1979] from data by Huschke [1969]. The humidities necessary for the calculation of the latent heat flux and longwave back radiation were obtained from an inverse calculation using this model and Fletcher's [1965] climatology for the Arctic. The results are not very sensitive to the humidity values. The snowfall rates used in the model are monthly climatological values compiled by Maykut and Untersteiner [1971]. The air temperatures are obtained from the monthly climatology of Crutcher and Meserve [1970], hereinafter referred to as the CM climatology; it is based on air temperatures for the period 

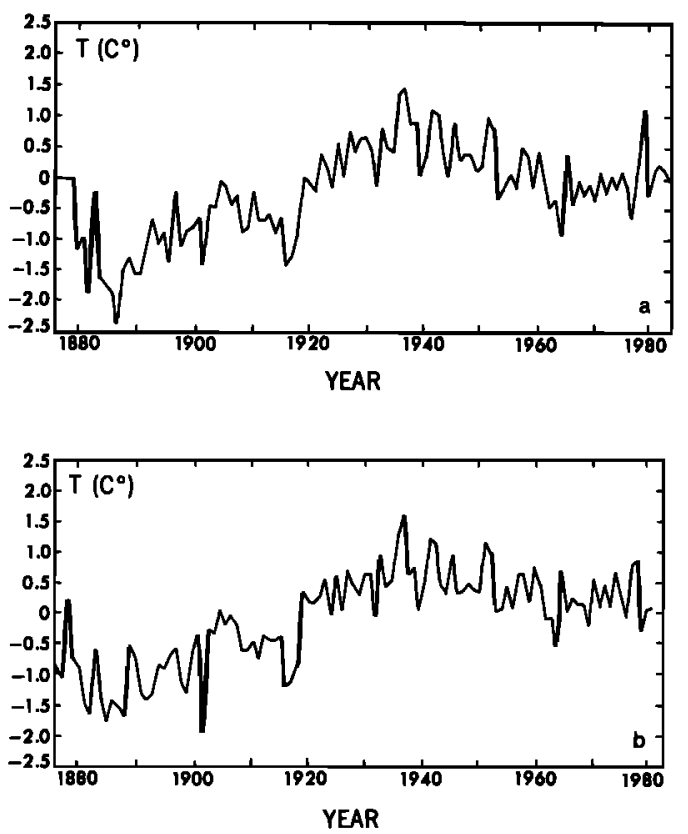

Fig. 2. (a) The annual air temperature anomalies from Hansen et al. $[1983,1988]$ for the northern hemisphere polar region. (b) The annual areally weighted air temperature anomalies north of $60^{\circ} \mathrm{N}$ from Wigley et al. [1981].

1931-1960. The air temperatures are areally averaged for the Arctic and are listed in Table 1.

The freshwater dilution of the upper layer necessary to maintain annual equilibrium of the upper ocean salinity was determined in the equilibrium simulation. This models the freshwater inflow to the Arctic, which is compensated by the divergence terms that appear in (2) and (3) to simulate the outflow of ice through the Fram Strait. The divergence estimate used in the model is based on the areal outflow value of $0.84 \times 10^{6} \mathrm{~km}^{2} / \mathrm{yr}$ by Moritz [1988], which divided by the area of Arctic, $1.2 \times 10^{7} \mathrm{~km}^{2}$, gives $2.3 \times 10^{-9} \mathrm{~s}^{-1}$. As a result there will be a small amount of open water present in the wintertime; however, this divergence does not represent the small-scale lead formation due to curl and divergence in the local wind field, which can be considerably larger.

The long-term simulations use two different data sets. The first one is from Hansen et al. [1983, 1988] covering the time period 1880-1985. This data set consists of monthly air temperature anomalies which are referenced to a climatology for the period 1950-1970. The time series for the annual mean of the anomalies is shown in Figure $2 a$. The model air temperatures are compiled by adding the monthly Hansen et al. anomalies (areally averaged) to the CM climatology. No correction was applied to the data set to account for the different reference level for the Hansen data set and the CM climatology so that the results can be compared to the results of Walsh et al. [1985].

The other data set used is from Wigley et al. [1981] and Kelly et al. [1982] covering the period 1851-1983. This data set also consists of temperature anomalies, which are referenced to an average over 1931-1950. The annual average of the areally averaged time series from this data set for the period $1880-1983$ is shown in Figure $2 b$. In the model, these values are adjusted to give the same average as the Hansen et al. data set for the period $1880-1984$; i.e., $0.1^{\circ} \mathrm{C}$ was subtracted uniformly from the Wigley et al. data.

The coolest period of the record was at the end of the last century and beginning of the present century. Subsequently, the climate experienced considerable warming, about $2^{\circ} \mathrm{C}$, by the 1940 s. From the 1940 s, there was a cooling trend which was not reversed until the mid-1960s. There are some differences in these two data sets, especially in the period from 1880 s to $1910 \mathrm{~s}$. The coldest year of the data set of Hansen et al. is 1887, whereas 1902 is the coldest year in the data set of Wigley et al. Differences are likely to arise from the scarseness of the data north of $60^{\circ} \mathrm{N}$ in this early period. After the $1930 \mathrm{~s}$, since more data were available, the two data sets appear to behave nearly identically.

\section{Results}

\section{Equilibrium Seasonal Cycle}

Since there are some differences, such as the forcing and boundary conditions at the ice-ocean interface, compared with the MK model, a climatological seasonal simulation is repeated. In this simulation we determine the amount of salinity to be removed from the water column to compensate, primarily, for the salt flux through the bottom of the ocean model and the horizontal export of ice. The ocean model describes only the upper 80-m water column; the bottom temperature $\left(-1.54^{\circ} \mathrm{C}\right)$ and salinity $(32.65 \mathrm{ppt})$ are kept constant.

The ice portion of the model requires about 30 years of spin-up, and at year 40 the upper ocean has also achieved seasonal equilibrium. The simulated equilibrium ice thickness corresponding to the climatology is $2.23 \mathrm{~m}$, which is below the observational value of about $3 \mathrm{~m}$ but is approximately the same as the result of Walsh et al. [1985], who used the same climatology. The maximum ice thickness is $2.75 \mathrm{~m}$ (in June), and the minimum is $1.77 \mathrm{~m}$ (in August). The net annual bottom accretion is $0.92 \mathrm{~m}$, the year long integral of $W_{I O}$ and $W_{F R}$, which is balanced by the remaining terms in (2). The term containing $\operatorname{div} U_{I}$ amounts to $0.10 \mathrm{~m}$. Observations show that the bottom accretion is about $50 \mathrm{~cm}$ [Maykut and Untersteiner, 1971]. The simulated high accretion-ablation rates can be justified for the whole basin because of the seasonal melt of the coastal ice of $1.5 \mathrm{~m}$ to 2.0 $\mathrm{m}$, covering $25 \%$ of the Arctic.

The salinity sink required to maintain annual equilibrium corresponds to the annual removal of $0.075 \mathrm{ppt}$ uniformly from the upper $80 \mathrm{~m}$. The river runoff of $0.110^{6} \mathrm{~m}^{3} \mathrm{~s}^{-1}$ [Aagaard and Greisman, 1975] corresponds to a salinity decrease of 0.1 ppt per year, if the fresh water is distributed uniformly in the upper water column. Thus $0.025 \mathrm{ppt}$ can to be attributed to saltier water sources such as the Bering Sea inflow. The salinity correction of $0.075 \mathrm{ppt}$ in the model compensates the sum of the salinization due to the surface salinity flux, -0.02 ppt (more discussion below); frazil ice formation in the water column, $0.07 \mathrm{ppt}$; and salinity flux through the bottom of the $80-\mathrm{m}$ slab, $0.025 \mathrm{ppt}$. The modelpredicted yearly surface salinity flux of $\mathbf{- 0 . 0 2} \mathrm{ppt}$, distributed evenly in an 8-m water column, is a sum of bottom accretion, top ablation, snowfall, and open water freeze-up. The contribution from the melting of the snow cover is about $-0.05 \mathrm{ppt}$ yearly, while the difference of $+0.03 \mathrm{ppt}$ is due to the export of ice out through the Fram Strait. Thus there is 


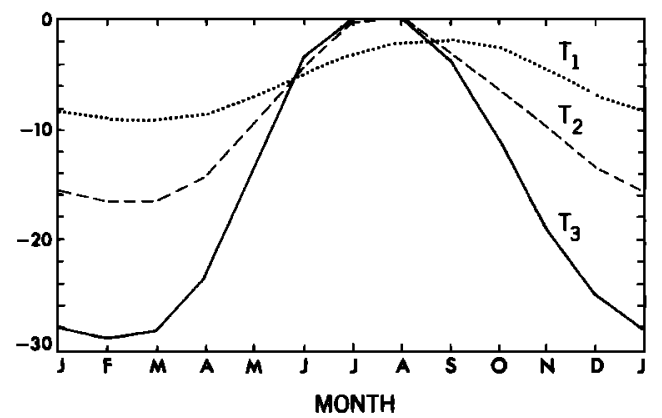

Fig. 3. The simulated seasonal variation of the snow surface, ice surface and internal ice temperatures $\left(T_{3}, T_{2}\right.$, and $T_{1}$, respectively), in degrees Celsius.

a net freshwater input at the surface which is balanced by the frazil ice production and consequent brine rejection amounting to $0.07 \mathrm{ppt}$ yearly, and by the bottom flux of $0.025 \mathrm{ppt}$ yearly. The annual reversal of the surface flux from negative to positive takes place in a short period, about 6 weeks. During this period the maximum salinity flux is nearly an order of magnitude larger than the absolute value of the annual mean salinity flux from ice freeze-up at the ice-ocean and air-ocean interfaces. The variability of the $80-\mathrm{m}$-depth salinity flux is negligible.

When the frazil ice formation is present, the upper ocean heat balance can be broken down into components of the annual average surface flux of $2.18 \mathrm{~W} \mathrm{~m}^{-2}$ (positive upward), heat release from the frazil ice formation of $2.12 \mathrm{~W}$ $\mathrm{m}^{-2}$, and the heat flux from the deeper ocean, $0.06 \mathrm{~W} \mathrm{~m} \mathrm{~m}^{-2}$ (without frazil ice formation the surface flux would be 0.06 $\mathrm{W} \mathrm{m}^{-2}$ ). This result supports the conclusions of Aagaard et al. [1981], who suggested that the heat release from the Arctic Atlantic layer is minimal.

Some results from this seasonal simulation are shown in Figures 3-6 for the snow and ice temperatures, ice concentration and average thickness $\left(A h_{I}\right)$ variation, and evolution of the temperature and salinity in the upper water column.

We also performed a simulation where the $\mathrm{CM}$ climatology is uniformly cooler by $0.5^{\circ} \mathrm{C}$, a value which is the difference between the CM climatology and the Hansen et al. data set for the period 1931-1960. As a result of the cooler climatology, the yearly average equilibrium ice thickness increased to $3 \mathrm{~m}$, which is about the observed value. Thus small changes in the air temperatures can affect the ice thickness; in this case the $0.5^{\circ} \mathrm{C}$ decrease corresponds to an

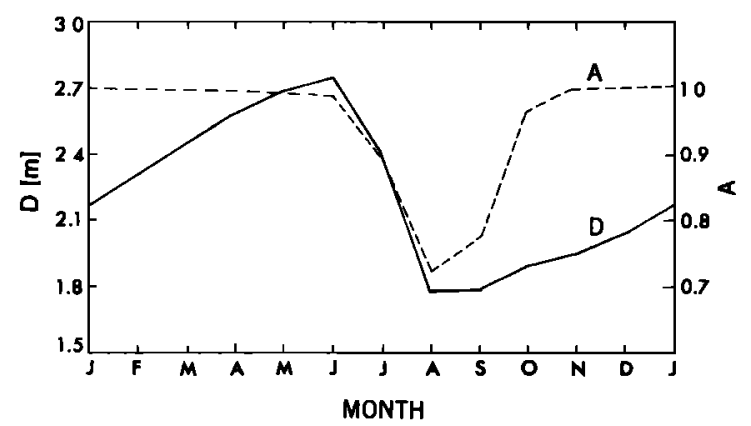

Fig. 4. Ice thickness $\left(D=A h_{I}\right)$ and concentration $(A)$ values from the seasonal equilibrium.

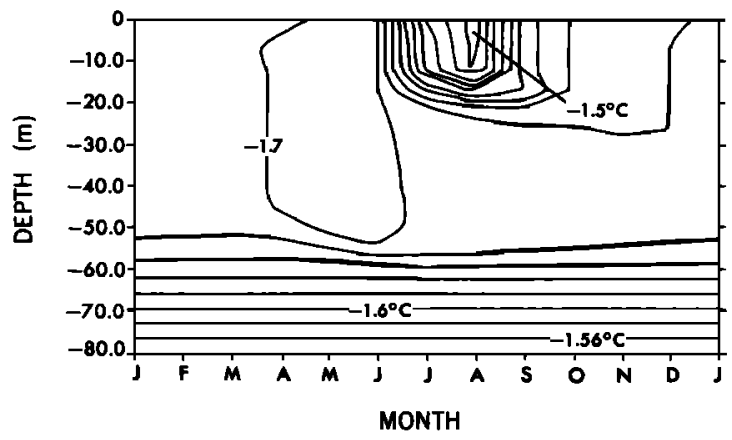

Fig. 5. Simulated seasonal equilibrium upper ocean temperature profile; contour interval is $0.02^{\circ} \mathrm{C}$.

increased storage of $0.7 \mathrm{~m}$ of fresh water in the area of $1210^{6}$ $\mathrm{km}^{2}$. The net annual bottom accretion decreased from 0.92 $\mathrm{m}$ to $0.77 \mathrm{~m}$. The increase of the mean ice thickness is caused by a reduced surface heat gain from the atmosphere. This effect is localized to the melting period where the atmospheric heat flux over the snow-ice cover increases from -438 to $-418 \mathrm{~W} \mathrm{~m}^{-2}$ in July and from -356 to $-342 \mathrm{~W} \mathrm{~m}^{-2}$ in August. Only about $5 \mathrm{~W} \mathrm{~m}^{-2}$ of this increase is a direct consequence of lowering air temperatures; most of the difference comes in July from the delayed albedo change from "dry snow" to wet snow and bare ice and in August from the reverse change occurring a few days earlier.

The salinity correction in response to the cooler climatol-

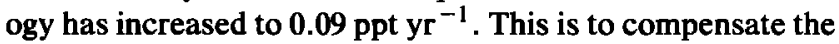
salinity contributions from the net surface salinity flux of $-0.01 \mathrm{ppt}$ yearly, from the frazil ice formation $\mathbf{0 . 0 6} \mathrm{ppt}$ and from the bottom flux of $0.04 \mathrm{ppt}$. Thus with a cooler climate the influence of the salinity flux from the deeper ocean becomes more important.

\section{Results Using the Hansen et al. Data}

The model runs are all spun up for 40 years using the climatology described in section 3, after which a 4-year linear transition is made to the air temperatures which are the sum of the CM climatology and the Hansen et al. anomaly field; we define this to be our standard case. The upper layer salinity correction as previously determined from the seasonal equilibrium simulation is kept constant for the long term simulation.

A test of model sensitivity to the initial conditions was done by using an estimate for air temperatures to be $-1^{\circ} \mathrm{C}$

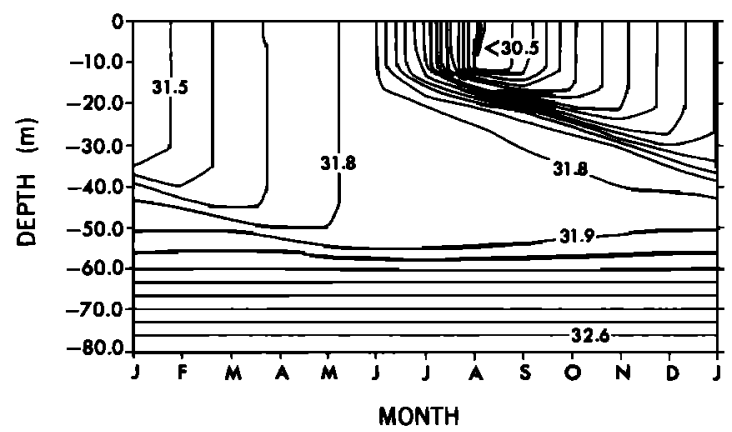

Fig. 6. Simulated seasonal equilibrium upper ocean salinity profile; contour interval is $0.1 \mathrm{ppt}$. 

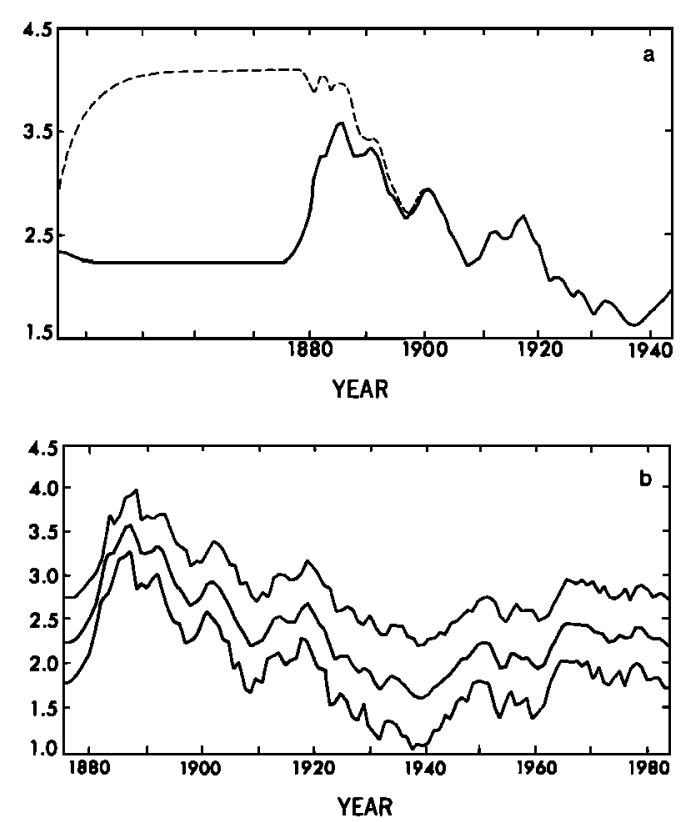

Fig. 7. (a) Ice thickness during spin-up of the standard case (solid line) together with the results from $1^{\circ} \mathrm{C}$ cooler climatology (dashed line). (b) The annual average ice thickness, together with summer minimum and winter maximum ice thickness during 1880-1985 from the simulation using the Hansen et al. data set. Units are meters.

lower than the CM climatology during the spin-up period. The ice thickness variation is shown in Figure $7 a$ together with the spin up and beginning of the standard case. After about 15 years the initial conditions are no longer important. It shows that the ice thickness adjusts very rapidly to the cooler temperatures relative to the initial conditions.

The results from the standard simulation using the Hansen et al air temperature anomaly data is shown in Figures $7 b$ to 10. The annual average ice thicknesses in Figure $7 b$ track the climatic trends, as expected, wherein the ice cover is minimal in the 1930s and early 1940s. The major growth periods occurred in the 1910s, 1940s and in the end of the 1960s. The annual minimum and maximum ice thicknesses are also shown in Figure $7 b$. The variability in the summer minimum ice thickness is more pronounced than in the winter maximum ice thickness; e.g., during 1961-1965 the minimum ice thickness increased by $0.64 \mathrm{~m}$ compared with the increase of $0.34 \mathrm{~m}$ in the maximum ice thickness. Compared with the observations from the last $30-40$ years, the model simulation contains an ice mass minimum in the early 1960s which is seen also in the Arctic ice extent data set compiled by Walsh and Johnson [1979]. It shows that around 1960 even the winter ice extent values were well below average; thus this minimum can be interpreted also as a minimum in the ice mass.

The annual volumetric fluxes $W_{A I}, W_{A O}, W_{I O}$, and $W_{F R}$ (weighted with ice concentration) contributing to the ice mass during this period are shown in Figure 8. While the integration of these fluxes produces ice thickness which closely follows climate fluctuations, the same trends in the individual fluxes are less evident. Figure 8 shows the largest fluctuations to be in $W_{A I}$, which is the surface melt flux and is strongly dependent on the air temperatures and consequently on the surface albedo and its timing. The under-ice

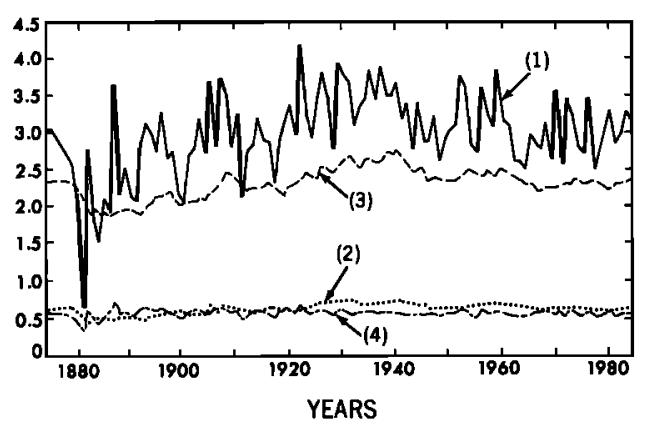

Fig. 8. The volumetric fluxes $A W_{A I}$ (curve 1), $W_{A O}$ (curve 2), $A W_{1 O}$ (curve 3), and $W_{F R}$ (curve 4), in $10^{-8} \mathrm{~m} \mathrm{~s}^{-1}\left(0.5 \times 10^{-8} \mathrm{~m}\right.$ $\mathrm{s}^{-1}$ is about $15 \mathrm{~cm} \mathrm{yr}^{-1}$ ) when the ice-ocean model is forced by the Hansen et al. data.

accretion rate $W_{I O}$ depends inversely on ice thickness (Figure $7 b$ ); the heat conduction decreases for thick ice reducing heat exchange at the interface and thus insulates the mixed layer. The open water freeze rate $W_{A O}$ and frazil ice accretion rate $W_{F R}$ show minimal variability, which for $W_{A O}$ is controlled by the limited yearly open water area.

As seen from the ice accumulation rates the surface salinity flux can be expected to be very sensitive to the interannual fluctuations in the climate. Figure $9 a$ depicts the annual surface salinity, frazil ice and bottom salinity fluxes (salinity fluxes are divided by $80 \mathrm{~m}$ ), which shows no climate trends in any of the salinity fluxes. However, the surface salinity flux has a considerable variability on both sides of the equilibrium value $\left(2 \mathrm{ppt} \mathrm{yr}^{-1}\right)$. To demonstrate the importance of the summer melt component in the annual mean, the maximum and minimum salinity fluxes are plotted in Figure $9 b$ in the same units together with the maximum wintertime brine rejection from combined congelate and frazil ice formation. It shows the enormous seasonal variability of the salinity fluxes: the minimum cooling season value (occurring nearly always in February) through the 100 -year period stays nearly constant, while most of the variability occurs in the melt season (the maximum occurs in July); thus the variation in the annual salinity flux is determined by the summer melt.

The variability in the salinity flux from frazil ice formation and in the salinity flux through the bottom of the ocean slab, shown in Figure 9a, is minimal. During the very heavy ice years, the frazil ice formation decreases due to decreased heat conduction. Also, with decreased ice melt (= heavy ice years) the upper ocean had a deepened mixing depth as reflected in decreased bottom flux. Overall, the variability of the bottom flux is very smooth as the strong, near surface variability diffuses downward.

To compare the surface salinity flux variability to the oceanic heat flux variability, we have plotted the average and wintertime maximum heat flux (excluding the heat released from frazil ice production) together with the summertime heat gain in Figure $9 c$, which shows that while the first two variables have little variation, the summertime oceanic heat gain has some interannual variability. Unlike the surface salinity flux, the summertime oceanic heat gain is of the same order as the wintertime values, which is why the annual average oceanic heat flux contains minimal variability. The seasonal variation of the oceanic heat flux is limited because most of the atmospheric heat gain is used to melt 

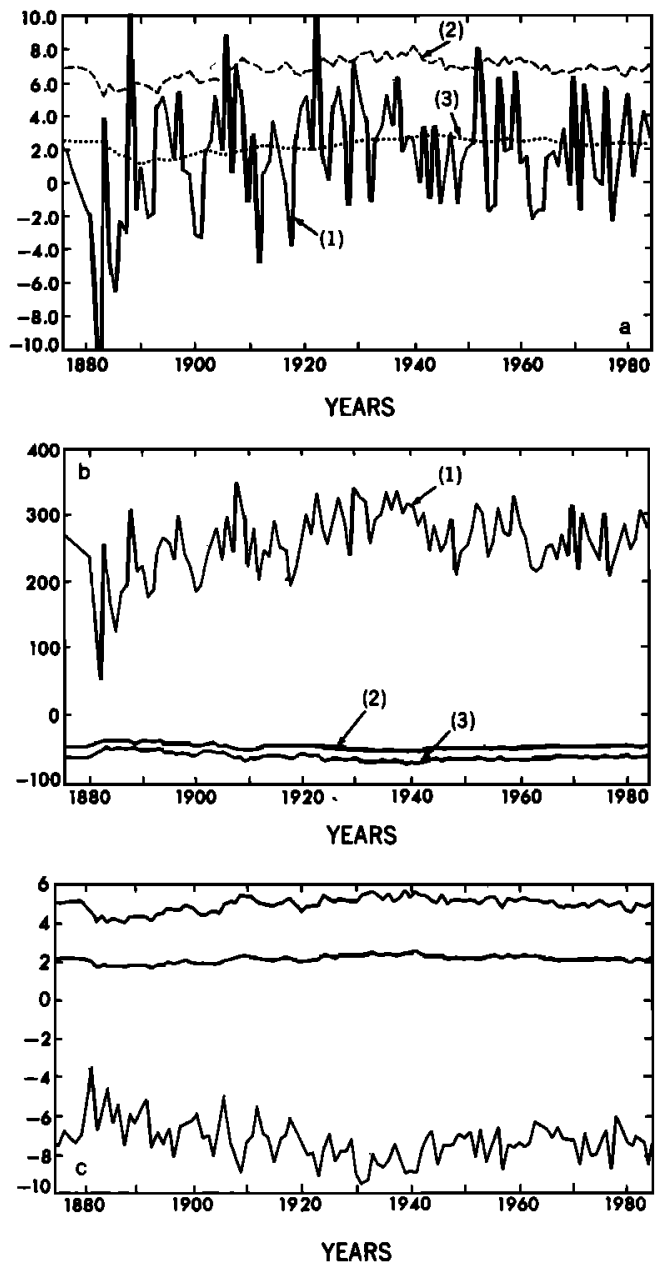

Fig. 9. Oceanic fluxes from the simulation with Hansen et al. data. Salinity fluxes are divided by the 80-m water column depth and are in units of $10^{-2}$ ppt per year. (a) Annual average surface salinity flux, excluding frazil ice contribution (curve 1), frazil ice salinity flux, $\int \sigma\left(S-S_{I}\right) d z$ (curve 2), and bottom salinity flux (curve 3). (b) Summer maximum salinity flux, i.e., freshwater flux (curve 1), winter minimum salinity flux (curve 2), and winter minimum salinity flux including frazil ice contribution (curve 3). (c) Annual average oceanic heat flux (middle curve), winter maximum heat flux (top curve) (heat flux from the frazil ice formation not included), and summertime minimum heat flux (bottom curve), in watts per square meter.

snow and ice instead of being absorbed into the mixed layer. Figure $9 c$ also implies that the ice cover has been a stable insulator of the deep ocean even though the changes in the surface air temperatures have changed by about $+4^{\circ} \mathrm{C}$ from the 1880 s to the 1930s. Figures $9 a$ and $9 b$ show that the large decrease in the summer melt occurred during the periods 1900-1905, 1910-1920, 1947-1950, and 1963-1970. This decrease in summer melt is also reflected in the minimum ice thickness changes which have a larger amplitude than the maximum ice thickness changes, with the summer ice thickness changes leading the changes in the winter ice thickness (Figure $7 b$ ).

The integrated effect of the salinity fluxes on the upper ocean is shown in Figure $\mathbf{1 0}$ for the simulated surface salinity record. It shows major freshenings to have occurred in 1905-1910, a long freshening trend corresponding to climate warming in the 1920s and 1930s, and the last one from 1950

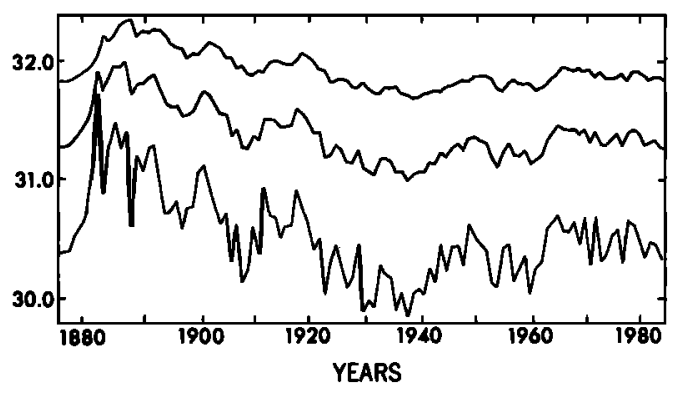

Fig. 10. Simulated annual average (middle curve), minimum (bottom curve), and maximum surface salinity (top curve), in parts per thousand.

to 1962 . Conversely, the surface salinity variations indicate rapid salinization of the surface waters in 1907-1920 and 1962-1970. These are, of course, periods of decreased summer melt.

\section{Results Using the Wigley et al. Data}

The Hansen et al. data and Wigley et al. data are quite similar, but applying them to force a numerical model may result in less similar model responses. Some results from the model run using Wigley et al. data are shown in Figures 11 and 12. The ice thickness (Figure 11) has stronger variations than in the standard simulation, especially for the ice growth periods around 1950 and 1965 . It is notable that the trend towards thicker ice beginning in 1940s has disappeared.

Ice growth and melt are directly reflected in the variation of the surface salinity flux and thus in the mixed layer salinity variations. The surface salinity is shown in Figure $12 a$, which is an integrated result of the surface salinity flux, frazil ice salinity flux, and bottom salinity flux (Figure $12 b$ ). While the simulated, surface salinity record appears to be very similar to the standard case, the period $1970-1983$ is quite different. Corresponding to the decrease in ice thickness there is a third separate freshening (about $0.2 \mathrm{ppt}$ ) of the mixed layer that occurred between 1970 and 1975. This part of the simulation resembles the Walsh et al. [1985] results using the Soviet data set [Vinnikov, 1977]. The dissimilarity in the annual surface salt flux in comparison with the standard case is more pronounced; the amplitudes of the variability have changed markedly even though the locations of the maxima and minima are nearly the same. This

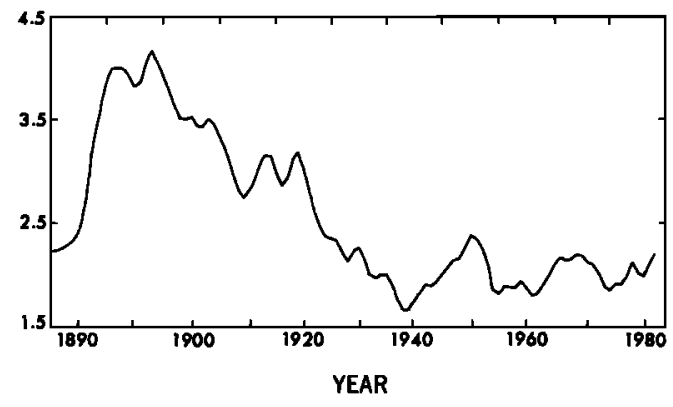

Fig. 11. Simulated annual average ice thickness (in meters) corresponding to the Wigley et al. data. 

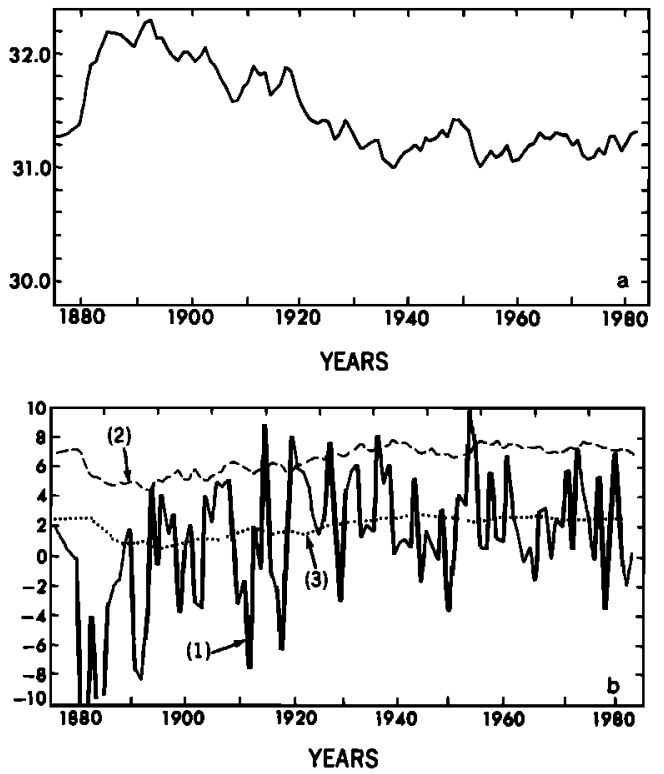

Fig. 12. Oceanic fluxes from the simulation with Wigley et al. data. (a) Simulated annual average surface salinity (in parts per thousand) and (b) surface salinity flux (excluding frazil ice contribution) (curve 1), frazil ice salinity flux (curve 2), and bottom salinity flux (curve 3), in $10^{-2}$ ppt per year (actual fluxes divided by $80 \mathrm{~m})$.

emphasizes the winter-summer contrast where small temperature differences between the two data sets in the summertime are reflected strongly in the annual averages. Moreover, the bottom salt flux, figure $12 b$, shows that the salinity gradient at $80 \mathrm{~m}$ depth nearly vanished, indicating that the depth of the mixed layer reached close to $80 \mathrm{~m}$ during the early period with very cool temperatures.

\section{Discussion}

The aim of this paper was to show that a one-dimensional coupled ice-ocean model is a helpful tool in predicting changes of the Arctic ice mass on climatic time scales based solely on the variation of surface air temperatures. The model allows one to calculate the ice accretion under the ice both from freezing at the ice-ocean interface and ice accumulation in the water column due to frazil ice formation. Seasonally, salinization due to the accretion of congelate and frazil ice is principally balanced by river runoff, which is determined by the model. It should be emphasized that the model yields one equilibrium state for the cyclical surface forcing and constant temperature and salinity at the bottom of the 80-m ocean slab.

The simulations for the period 1880-1985 show large variability in the ice thickness and in related quantities such as mixed layer salinity. Records on ice variability are quite sparse before the 1950s; the Icelandic ice index, shown in Figure 13 from Kelly et al. [1987] (see also Lamb [1977]) is the only reference going back as far as the 1800 s. It represents ice persistence around the Icelandic coastal waters. Of course, our model results do not directly apply to the Icelandic region. However, it is the only observational evidence of the past ice conditions available for comparison. Since a high percentage of the sea ice in the Greenland-

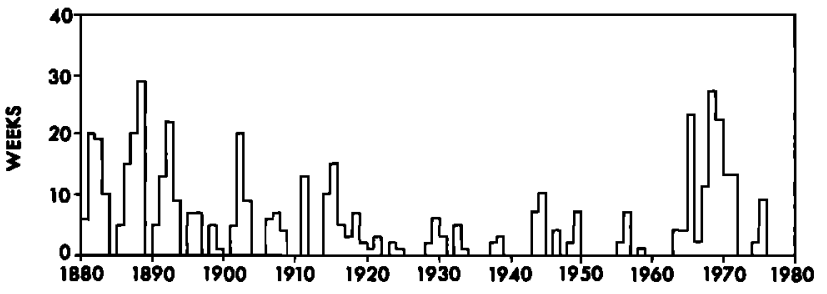

Fig. 13. The Icelandic sea ice record from 1880-1980 from Kelly $e t$ al. [1987]. Ice severity is measured in the number of weeks when ice affected the Icelandic coastal waters.

Iceland region is transported from the central Arctic, we reason that any changes in the Arctic ice mass should be reflected in the ice conditions in the Greenland and Iceland seas. Indeed, there is a strong similarity between Figure 13 and the model predicted ice thickness variations in Figure $7 b$, where extensive periods of ice occurrence in the Icelandic waters correspond to the increased Arctic ice mass in the model simulation. Because local effects are included to the ice index, some differences are expected, such as in the late $1960 \mathrm{~s}$, when the ice index shows a much larger trend toward higher ice occurrence. Since the simulated record is computed on the basis of the average polar region air temperature, our results offer evidence that the Icelandic ice record can be interpreted as a measure of a broader polar region climate trend. Kelly et al. [1987] concluded otherwise; they suggested that the ice index is a climate indicator of only the North Atlantic sector. Their conclusions were based on correlations with ice concentration in the adjacent seas. It is our opinion that ice concentration is a relatively weak climate indicator compared with ice thickness.

Comparison of these model results with results from a three-dimensional model for the period 1951-1960 using the same air temperatures [Walsh et al., 1985] show both models producing very similar behavior. This suggests that the ice dynamics plays a minor role in the interannual variability of the total Arctic ice mass and mainly affects the regional ice thickness distribution.

As was suggested by Parkinson and Kellogg [1979], model simulations show that the variation in summer air temperatures is more important to the Arctic than the variations in the winter temperatures. An even modest air temperature increase results in faster snow melt and an earlier albedo decrease, after which the influence of the increased sensible heat flux diminishes in relation to the enhanced absorption of short-wave radiation. Thus interannually, the onset of snow melt modulates the length of the melting season and determines the total ice melt. The melt is further amplified by the very low albedo of open water. As a conclusion, these model simulations show that the summer ice melt varies interannually with much larger amplitude than the total seasonal ice growth, so that the variation of the annual average ice thickness (= ice mass) is determined by the summer melt. Furthermore, the model simulations show continuous static stability of the upper water column and survival of the ice cover during the past hundred years where the maximum change from 1885 to 1935 amounted to about $4^{\circ} \mathrm{C}$. The annual oceanic heat flux from the deep ocean and the maximum freezing rate and associated nearly constant minimum surface salinity flux did not vary significantly. Any changes in 
the stability of the water column would affect considerably both of these quantities. This finding also implies that the oceanic influence on the Arctic ice mass is minimal for the range of atmospheric variability tested, even though one would expect that perturbations of the large seasonal signal in the ocean would be important. In spite of large variations in the mixed layer salinity (and thus in density) as simulated, the stratification is so strong that exchange of salt and heat with the deep ocean is negligible.

Strong freshening events of the mixed layer and deeper waters have been observed in the subpolar gyre around 1910 and 1970 [Dickson et al. 1988] which were also heavy ice years in the Icelandic waters [Lamb, 1977]. It has been suggested that the increased ice mass exported from the Arctic may play a role. For instance during 1961-1965 the model-simulated increase in the summer ice thickness is greater than $0.6 \mathrm{~m}$. Transporting thicker than usual summer ice from the Arctic may interfere very strongly with the fall mixing of the upper water column in the Greenland and Iceland seas, which are the formation regions of intermediate water masses flowing to the main Atlantic [Swift and Aagaard, 1981].

Acknowledgments. We gratefully acknowledge support from the Office of Naval Research Arctic Programs, grant \#N00014-64-K0640, and from the NOAA Geophysical Fluid Dynamics Laboratory (GFDL), where S.H. was a visiting scientist under NOAA/Princeton grant NA87EA-D-00039. We wish to thank Kirk Bryan for valuable discussions. Also, we wish to thank Johann Callan and the GFDL Drafting department for their help in the manuscript preparation.

\section{REFERENCES}

Aagaard, K., and P. Greisman, Toward new mass and heat budgets for the Arctic Ocean, J. Geophys. Res., 80, 3821-3827, 1975.

Aagaard, K., L. K. Coachman, and E. C. Carmack, On the halocline of the Arctic Ocean, Deep Sea Res., Part A, 28, 529-545, 1981.

Blumberg, A. F., and G. L. Mellor, Diagnostic and prognostic numerical circulation studies of the South Atlantic Bight, $J$. Geophys. Res., 88, 4579-4592, 1983.

Blumberg, A. L., and G. L. Mellor, A description of a threedimensional coastal ocean circulation model, in ThreeDimensional Coastal Ocean Models, Coastal and Estuarine Sci., vol. 4, edited by N. S. Heaps, pp. 1-16, AGU, Washington, D. C., 1987.

Bourke, R. H., and R. P. Garrett, Sea ice thickness distribution in the Arctic Ocean, Cold Reg. Sci. Technol., 13, 259-280, 1987.

Crutcher, H. L., and J. M. Meserve, Selected level heights, temperatures and dew points for the northern hemisphere, Rep. 50-IC-52, U.S. Nav. Weather Serv. Command, Washington, D. C., 1970.

Dickson, R. R., J. Meincke, S.-A. Malmberg, and A. J. Lee, The 'great salinity anomaly' in the northern North Atlantic 1968-1982, Prog. Oceanogr., 20, 103-151, 1988.

Englebretson, R. E., and J. E. Walsh, Fram Strait ice flux calculations and associated ice conditions, Geojournal, 18.1, 61-67, 1989.

Fletcher, J. O., The heat budget of the Arctic basin and its relation to climate, Rep. $R-444-P R, 179$ pp., Rand Corp., Santa Monica, Calif., 1965.

Goody, R., Polar processes and world climate, Mon. Weather Rev., $108,1935-1942,1980$.

Gorshkov, S. G. (Ed.), World Ocean Atlas, vol. 3, Arctic Ocean, Pergamon, New York, 1983.

Hansen, J., D. Johnson, A. Lacis, S. Lebedeff, P. Lee, D. Rind, and G. Russell, Climatic effects of atmospheric carbon dioxide, Science, 220, 873-875, 1983.

Hansen, J., I. Fung, A. Lacis, D. Rind, S. Lebedeff, R. Ruedy, G. Russell, and P. Stone, Global climate changes as forecast by
Goddard Institute for Space studies three-dimensional model, $J$. Geophys. Res., 93, 9341-9364, 1988.

Hibler, W. D., III, A dynamic thermodynamic sea ice model, $J$. Phys. Oceanogr., 9, 815-846, 1979.

Huschke, R. E., Arctic cloud statistics from "air-calibrated" surface weather observations, Memo. $R M-6173-P R, 79$ pp., Rand Corp., Santa Monica, Calif., 1969.

Kelly, P. M., P. D. Jones, C. B. Sear, B. S. G. Cherry, and R. K. Tavakol, Variations in surface air temperatures, part 2, Arctic regions, 1881-1980, Mon. Weather Rev., 110, 71-83, 1982.

Kelly, P. M., C. M. Goodness, and B. S. G. Cherry, The interpretation of the Icelandic sea ice record, J. Geophys. Res., 92, $10,835-10,843,1987$.

Killworth, P. D., and J. M. Smith, One-and-a-half-dimensional model for the Arctic halocline, Deep Sea Res., Part A, 31, 271-294, 1984.

Lamb, H. H., Climate: Present, Past, and Future, vol. 2, Methuen, London, 1977.

Ledley, T., For a lead-temperature feedback in climatic variation, Geophys. Res. Lett., 15, 36-39, $1988 a$.

Ledley, T., A coupled energy balance climate-sea ice model: Impact of sea ice and leads on climate, J. Geophys. Res., 93, $15,919-15,935,1988 b$.

Manabe, S., and R. J. Stouffer, Sensitivity of a global climate model to an increase of $\mathrm{CO}_{2}$ concentration in the atmosphere, $J$. Geophys. Res., 85, 5529-5554, 1980.

Maykut, G. A., Energy exchange over young sea ice in the central Arctic, J. Geophys. Res., 83, 3646-3658, 1978.

Maykut, G. A., Large scale heat exchange and ice production in the central Arctic, J. Geophys. Res., 87, 7971-7984, 1982.

Maykut, G. A., and N. Untersteiner, Some results from a timedependent thermodynamic model of sea ice, J. Geophys. Res., 76, 1550-1575, 1971.

Mellor, G. L., and L. H. Kantha, An ice-ocean coupled model, $J$. Geophys. Res., 94, 10,937-10,954, 1989.

Mellor, G. L., and T. Yamada, A hierarchy of turbulence closure models for planetary boundary layers, J. Atmos. Sci., 31, 17911896, 1974.

Mellor, G. L., and T. Yamada, Development of a turbulence closure model for geophysical fluid problems, Rev. Geophys., 20(4), 851-875, 1982.

Moritz, R. E., The ice budget of the Greenland Sea, Tech. Rep. APL-UW TR 8812, Appl. Phys. Lab., Univ. of Washington, Seattle, 1988.

Oey, L.-Y., G. L. Mellor, and R. I. Hires, A three dimensional simulation of the Hudson-Raritan estuary, Part I, Description of the model and model simulations, J. Phys. Oceanogr., 15, 1676-1692, 1985.

Parkinson, C. L., and W. W. Kellogg, Arctic sea-ice decay simulated for a $\mathrm{CO}_{2}$-induced temperature rise, Clim. Change, 2, 149-162, 1979.

Parkinson, C. L., and W. M. Washington, A large-scale numerical model of sea ice, J. Geophys. Res., 84, 311-336, 1979.

Parkinson, C. L., J. C. Comiso, H. J. Zwally, D. J. Cavalieri, P. Gloersen, and W. J. Campbell, Arctic sea ice 1973-1977, NASA Spec. Publ. 489, 1987.

Semtner, A. J., A model for the thermodynamic growth of sea ice in numerical investigation of climate, $J$. Phys. Oceanogr., 6, 379-389, 1976.

Semtner, A. J., A numerical study of sea ice and ocean circulation in the Arctic, J. Phys. Oceanogr., 17, 1077-1099, 1987.

Sigtryggson, $\mathrm{H}$., An outline of sea ice conditions in the vicinity of Iceland, Jokull, 22, 1-11, 1972.

Steele, M., G. L. Mellor, and M. G. McPhee, The role of the molecular sublayer in the melting or freezing process, $J$. Phys. Oceanogr., 19, 139-147, 1989.

Stigebrandt, A., A model for the thickness and salinity of the upper layer in the Arctic Ocean and relationship between ice thickness and some external parameters, J. Phys. Oceanogr., 11, $1407-1422,1981$.

Swift, J. H., and K. Aagaard, Seasonal transitions and water mass formation in the Iceland and Greenland Seas, Deep Sea Res., Part A, 28, 1107-1129, 1981 .

Vinje, T. E., and O. Finnekåsa, The ice transport through Fram Strait, NR. 186, 39 pp., Norsk Polarinst. Skrifter, Oslo, 1986.

Vinnikov, K. Y., On the problem of the method for obtaining and 
interpreting data on surface air temperature in the northern hemisphere during period 1881-1975, Meteorol. Gidrol., 9, 110-114, 1977.

Vowinckel, E., Ice transport in the East Greenland current and its causes, Arctic, 17, 111-119, 1964.

Wadhams, P., The underside of Arctic sea ice imaged by sidescan sonar, Nature, 333, 161-164, 1988.

Walsh, J. E., and C. M. Johnson, An analysis of Arctic sea ice fluctuations 1953-1977, J. Phys. Oceanogr., 9, 580-591, 1979.

Walsh, J. E., W. D. Hibler, III, and B. Ross, Numerical simulation of northem hemisphere sea ice variability, 1951-1980, J. Geophys. Res., 90, 4847-4865, 1985.
Wigley, T. M. L., P. D. Jones, and P. M. Kelly, Global warming? Nature, 291, 285, 1981.

S. Häkkinen and G. L. Mellor, Princeton University, P.O. Box CN710, Sayre Hall, Princeton, NJ 08544.

(Received August 21, 1989; revised February 22, 1990; accepted March 8, 1990.) 